\title{
O SIGILO DOS ARQUIVOS VINCULADOS AO REGIME MILITAR E O DIREITO CONSTITUCIONAL À INFORMAÇÃO: uma questão de cidadania
}

André Pinto Baracchini ${ }^{1}$

RESUMO: O presente artigo versa sobre a necessidade de se dar transparência aos arquivos produzidos durante a ditadura militar, uma vez que através de tal instrumento, o povo terá a possibilidade de resgatar fatos deste período que ainda não restam plenamente elucidados, propiciando uma identificação maior com a nação e adequando as instituições ao Estado Democrático de Direito e ao conseqüente respeito à Constituição Federal.

PALAVRAS-CHAVE: Ditadura Militar. Informação. Cidadania.

The Secrecy of Links to the Archives the Military Regime and Constitutional Right to Information: a Question of Citizenship

ABSTRACT: This article is about the need to give transparency to the files produced during the military dictatorship, because through this instrument, the people will be able to redeem facts of this period that have not yet left fully elucidated, providing a greater identification with the nation and enhancing the institutions of a democratic state and the consequent to the Federal Constitution.

KEY-WORDS: Military Ditadura. Information. Citizenship.

\section{INTRODUÇÃO}

No espaço de tempo compreendido entre 1964 e 1985, o Brasil inseriu-se em um dos mais longos e obscuros períodos de exceção ocorridos no continente. O regime militar brasileiro instaurou uma ordem frontalmente diversa da democrática, agindo no sentido de tolher as liberdades fundamentais do povo, fazendo uso de ampla campanha de censura aos meios de comunicação, às manifestações artísticas, políticas, intelectuais ou qualquer outro fato que desse vazão a um ideário diverso do considerado seguro à manutenção do regime ora instalado. Uma verdadeira carnificina ocorria nos "porões da ditadura" enquanto destinavam-se, compulsoriamente, páginas e páginas de jornais para a publicação de receitas culinárias.

Neste panorama, é fato amplamente conhecido que o Estado de então iniciou processo de aparelhamento de órgãos de controle e monitoramento ideológico da população, tais como o SNI (Serviço Nacional de Informações), o DOI-CODI (Departamento de Operações e Informações do Exército). Tal iniciativa visava à

1 Acadêmico do $5^{\circ}$ semestre do Curso de Direito da Universidade Federal de Santa Maria. E-mail: andrebaracchini@hotmail.com. 
obtenção de informações a respeito de indivíduos potencialmente contrários à ditadura e que, conforme o grau do risco que ofereciam, eram presos e mortos nos estabelecimentos militares. Todo este procedimento, desde a colheita de informações até a prática dos atos de tortura e as conseqüentes mortes daí advindas eram minuciosamente detalhados aos superiores hierárquicos através de documentos os quais, em sua grande maioria, são desconhecidos do povo brasileiro.

Importante salientar ainda que fora vasta a produção documental a registrar os atos rotineiros da administração estatal, denotando como se dava a relação que o Estado nutria consigo - como burocracia estatal em si - e com a sociedade civil.

Indubitavelmente, é direito do povo e uma forma de busca à cidadania, a possibilidade de se ter acesso pleno e sem distorções aos acontecimentos que ocorreram outrora no Estado a qual pertençam. Mais do que isso, o acesso às informações relativas a fatos passados é um instrumento imprescindível à identificação do indivíduo no ambiente em que gravita, de forma a fortalecer o seu vínculo com a nação a que pertence. Nada mais justo e saudável à democracia.

Também, é imperioso que o Estado brasileiro, responsável pelas atrocidades já anteriormente descritas, preste contas às inúmeras famílias que foram alijadas do convívio de seus membros, muitos deles ainda em tenra idade, famílias as quais hoje convivem com a sombra da incerteza a respeito do paradeiro de seus familiares, muitas alimentando esperanças de que seu ente ainda esteja vivo, outras, apenas nutrindo o desejo de propiciar um enterro digno aos seus parentes.

Ademais, importante que não se sonegue o relevante papel que exerce o conhecimento minucioso de acontecimentos tão nocivos aos valores que hoje se apresentam em fase de consolidação, como os que fundamentam o Estado Democrático de Direito e o respeito aos direitos humanos, vez que a geração atual, conhecedora dos erros do passado e sabendo das conseqüências que poderão advir, sendo diligente, certamente evitará a repetição dos absurdos ocorridos em outros tempos.

\section{LEI DA ANISTIA: CAMINHO DA DEMOCRACIA OU TRIBUTO À IMPUNIDADE?}


Como parte de um processo de abertura política lenta, gradual e segura, segundo as conhecidas palavras proferidas pelo general presidente Ernesto Geisel (1908-1996), a Lei $\mathrm{n}^{\mathrm{o}}$ 6.683, mais conhecida como Lei da Anistia foi promulgada em 28 de agosto de 1979, sob a presidência do general João Baptista Figueiredo - antigo chefe do SNI - e foi considerada por muitos um razoável avanço democrático frente ao contexto de então, isto porque reiteradas vezes o MDB (Movimento Democrático Brasileiro), partido de "oposição" ao regime, tentara anteriormente a edição da referida lei, contudo, sucumbindo à intolerância daqueles tempos.

Porém, não são poucas as críticas ao diploma legal em análise. Neste sentido, argumenta Comparato (2004), que a lei da anistia fora feita pelos próprios militares, naturalmente possibilitando distorções, tais como o fato de além de anistiar os indivíduos que tivessem cometido crimes políticos segundo a tipificação vigente à época, a lei mantinha impunes os agentes do Estado que potencialmente fizeram uso de qualquer espécie de violência contra os opositores. Ademais, o eminente jurista sustenta que “... não poderia continuar em vigor depois da redemocratização do país. Além disso, em 1992, o Brasil ratificou a Convenção Americana de Direitos Humanos, de 1969, que torna imprescritíveis os crimes de tortura", referindo-se à incompatibilidade da lei da Anistia no tocante à impunidade dos agentes estatais responsáveis pela tortura, com a emergente ordem democrática. Tais desvios contidos na lei são potencializados pela sociedade, que, segundo o mesmo jurista “... se eles estão impunes, é por causa da hesitação geral, inclusive das vítimas". Conforme entendimento do historiador Alencastro (2003):

\footnotetext{
A questão é que todo o debate está focado nas vítimas, quando também se deveria discutir o destino dos torturadores. Sobre eles, nunca houve formalização de qualquer acusação. Enquanto o debate se restringir ao drama humanitário das vítimas, os torturadores continuarão impunes. E isso é uma tragédia ética para o Brasil. (ALENCASTRO, 2003).
}

\section{A ATUAL POSTURA DO GOVERNO BRASILEIRO}

\subsection{Comissão de Mortos e Desaparecidos Políticos}

Lamentavelmente, entre os anos de 1985 até a metade da década de 1990, muito pouco foi feito em relação à divulgação de documentos da época do regime militar e, conseqüentemente, tampouco no tocante à responsabilização dos agentes torturadores a 
serviço do Estado ditatorial. Note-se que o país ainda temia uma contra-reação à volta do Estado Democrático de Direito, de forma que a caserna ainda detinha considerável ingerência, mesmo que velada, sobre política brasileira, não sendo conveniente naquele momento, alterações significativas no sistema projetado em 1979 pelos militares. Com a consolidação gradativa das instituições democráticas no país - mesmo com alguns percalços - naturalmente criou-se ambiente favorável à elaboração de regramento um pouco mais de efeitos concretos e com vistas aos desaparecidos políticos. Nesta esteira, em 1995 foi promulgada a Lei ${ }^{\circ} 9.140$ prevendo a responsabilização do Estado por mortes e desaparecimentos derivados de perseguição política entre os anos de 1961 e 1985, criando-se, na ocasião, a Comissão de Mortos e Desaparecidos Políticos. Porém, a referida lei não trouxe contribuição relevante para o objetivo de trazer a público informações atinentes ao regime militar, de forma a dificultar, por isto, o seu objetivo principal, qual seja de apurar a responsabilidade do Estado pelas mortes e desaparecimentos de perseguidos políticos frente à escassez de documentação comprobatória.

\subsection{Comissão ligada ao Ministério da Justiça:}

Em 28 de agosto de 2001 foi criada uma Comissão de Anistia, composta por dez membros, vinculada diretamente ao Ministério da Justiça, através da Medida Provisória $\mathrm{n}^{\mathrm{o}} 2.151$ que prevê reparação financeira para aqueles indivíduos que sofreram retaliações dos governos de exceção constituídos no Brasil. Destaque-se que no presente caso, o período de abrangência da indenização é maior, 1946-1988, sendo que, além do regime militar de 1964-1985, esta lei também abarcou o período do governo de Getúlio Vargas. Ademais, a referida lei é mais abrangente, isto porque além da indenização pelos danos materiais e morais sofridos pelos perseguidos políticos, o diploma legal prevê medidas mitigadoras in concreto, ainda que parcialmente, dos transtornos causados, sendo que as vítimas poderão ter direito a reingressar na função que porventura foram demitidas por razões de cunho ideológico e à contagem do respectivo tempo de serviço quando de seu afastamento injusto, dentre outras iniciativas reparadoras. Subsidiariamente, foi promulgada a lei $\mathrm{n}^{\circ} 10.559$ de 2002 que vem regulamentar o art. $8^{\circ}$ dos Atos das Disposições Constitucionais Transitórias, prescrevendo que a reparação poderá ser através de parcela única correspondente a 30 salários mínimos por ano de perseguição 
até o limite de 100 mil reais, ou a remuneração correspondente ao valor que o prejudicado receberia na função que ocupava quando de sua cassação, naturalmente proporcional ao posto que hoje ocuparia, sendo que tudo limitado ao teto salarial dos funcionários federais.

\subsection{Comissão Interministerial:}

Criada em 2003, com prazo de 120 dias, foi motivada pelo descontentamento geral da população diante do recurso, flagrantemente descabido e inoportuno a meu ver, apresentado pelo Advogado Geral da União, contra a sentença da juíza da $1^{a}$ Vara da Justiça Federal de Minas Gerais que permitia aos parentes dos mortos na Guerrilha do Araguaia, organizada pelos militantes do PC do B (Partido Comunista do Brasil), o conhecimento das informações relacionadas às operações de combate realizadas pelos órgãos de repressão estatais, e que culminaram por dizimar a dita insurgência na década de 1970. O argumento do Advogado Geral da União é que a julgadora de primeira instância teria extrapolado os limites do pedido, sendo que a decisão recorrida deveria limitar-se a dizer se existiam documentos em posse do ente público capazes de facilitar a localização dos restos mortais dos guerrilheiros. $\mathrm{O}$ argumento usado no recurso é descabido uma vez que a magistrada, sem ter acesso à integralidade dos documentos, por lógico, nunca teria a possibilidade de fazer o exame da existência ou não de tais documentos inerentes às vítimas. Não poderia ser outra a decisão da juíza. Note-se que o recurso em análise, ao menos em minha concepção, possui intuito procrastinatório, deixando clara a má vontade do Executivo em lançar luzes aos casos de atrocidades cometidos outrora pelo Estado brasileiro, prolongando injustificadamente e abusivamente a dor das famílias que promoveram a ação. Como já bem denota o nome, a comissão era interministerial, pondo-se como verdadeira força-tarefa na persecução de documentos atinentes às vítimas. Conforme o Decreto $\mathrm{n}^{\circ} 4.850$, de 2 de outubro de 2003 que regulamenta a dita comissão, os responsáveis pela pesquisa teriam acesso irrestrito aos documentos do regime militar, inclusive aos de caráter sigilosos. Os documentos produzidos pela comissão ficariam em poder do Ministério da Justiça, de forma que o Ministro da Justiça terá a incumbência de, se for o caso, reclassificar os documentos quanto ao seu grau de sigilo. Porém, até o presente momento e a despeito do prazo 
estabelecido para o término e apresentação de resultados, não foram manifestadas quaisquer conclusões a respeito.

\subsection{Comissão de Averiguação e Análise de Informações Sigilosas:}

Subordinada ao Ministério da Casa Civil, foi instituída pela lei no 11.111 de 2005 - lei originária da conversão da Medida Provisória 228 de 2004, a qual modifica alguns poucos artigos da lei 8.159/91 que regrava anteriormente as restrições dos documentos dispositivo o qual veio a regulamentar a exigência do artigo $5^{\circ}$, XXXIII da Constituição Federal, a respeito da necessidade de regramento do sigilo necessário à segurança da sociedade e do Estado, possui a atribuição de administrar os documentos ultra secretos e avaliar o tempo que deverão permanecer com tal restrição. Ademais, esta comissão responsabilizou-se em fazer a transferência dos arquivos depositados na ABIN (Agência Brasileira de Inteligência) para o Arquivo Nacional. Tais arquivos resultaram da produção entre 1964-1990 do SNI (Serviço Nacional de Informações), do CSN (Conselho Nacional de Segurança) e da CGI (Comissão Geral de Investigações). A grande crítica que permanece sendo feita é a respeito de os documentos continuarem sob a tutela do governo federal. Desde a criação da primeira comissão em 1995, muito pouco se progrediu em relação à divulgação dos arquivos. Conforme já analisado anteriormente, é clara a má vontade e leniência da União em ao menos flexibilizar os critérios de classificação quanto ao sigilo da referida documentação. A questão crucial é que, tendo a União pouco ou nenhum interesse na transparência dos fatos ocorridos durante o regime de exceção, jamais poderia deter a guarda de tais documentos. É de extrema incoerência. Neste sentido, vejamos parte da lei em comento e da lei $n^{\circ} 8.159 / 91$

Lei 11.111 de 05 de maio de 2005

(...)

Art. $4^{\circ}$ O Poder Executivo instituirá, no âmbito da Casa Civil da Presidência da República, Comissão de Averiguação e Análise de Informações Sigilosas, com a finalidade de decidir sobre a aplicação da ressalva ao acesso de documentos, em conformidade com o disposto nos parágrafos do art $6^{\circ}$ desta Lei.

(...)

Art. $6^{\circ} \mathrm{O}$ acesso aos documentos públicos classificados no mais alto grau de sigilo poderá ser restringido pelo prazo e prorrogação previstos no $\$ 2^{\circ}$ do art. 23 da Lei $n^{o} 8.159$, de 8 de janeiro de 1991.

(...)

C 2008. Departamento de Direito da UFSM. Todos os direitos reservados. 
$\S 2^{\circ}$ Antes de expirada a prorrogação do prazo de que trata o caput deste artigo, a autoridade competente para a classificação do documento no mais alto grau de sigilo poderá provocar, de modo justificado, a manifestação da Comissão de Averiguação e Análise de Informações Sigilosas para que avalie se o acesso ao documento ameaçará a soberania, a integridade territorial nacional ou as relações internacionais do País, caso em que a Comissão poderá manter a permanência da ressalva ao acesso do documento pelo tempo que estipular.

(...).

Lei $n^{o} 8.159$, de 8 de janeiro de 1991

(...)

Art. 23. Decreto fixará as categorias de sigilo que deverão ser obedecidas pelos órgãos públicos na classificação dos documentos por eles produzidos.

$\S 1^{o}$ Os documentos cuja divulgação ponha em risco a segurança da sociedade e do Estado, bem como aqueles necessários ao resguardo da inviolabilidade da intimidade, da vida privada, da honra e da imagem das pessoas são originariamente sigilosos.

$\S 2^{\circ} \mathrm{O}$ acesso aos documentos sigilosos referentes à segurança da sociedade e do Estado será restrito por um prazo máximo de 30 (trinta) anos, a contar da data de sua produção, podendo esse prazo ser prorrogado, por uma única vez, por igual período.

$\S 3^{\circ} \mathrm{O}$ acesso aos documentos sigilosos referente à honra e à imagem das pessoas será restrito por um prazo máximo de 100 (cem) anos, a contar da sua data de produção.

(...).

(Grifos meus)

Note-se que é flagrante e excessiva a concentração de poder sobre a divulgação dos arquivos nas mãos da União, seja através da própria comissão ou mesmo em relação ao Ministério que gerencia os trabalhos da mesma. O governo argumenta que, conforme o art. $23, \S 2^{\circ}$ da lei 8.159/91, os documentos que completaram 30 anos, contados da data em que foram produzidos, já poderiam perfeitamente virem a público. Portanto, conforme este entendimento, os arquivos produzidos até a data de julho de 1978 estariam plenamente habilitados à publicidade. Tal raciocínio é, indubitavelmente, falacioso, uma vez que a União se reserva o direito de, quando considerar necessário quesito de extrema subjetividade - poder prorrogar a restrição ao acesso dos documentos, ou seja, toda vez que o governo entender conveniente tolher o acesso às ditas informações, poderá fazer sem esbarrar em qualquer natureza de critérios anteriormente estabelecidos, tornando a disposição legal inócua, ao menos por hora. Como já salientei anteriormente, sem pecar pelo exagero, é urgente que as informações do período de exceção sejam divulgadas. Ademais, são de conhecimento público notícias no sentido de que estaria ocorrendo em determinadas unidades das forças armadas, a queima de documentos da época do regime militar. Lembre-se do caso ocorrido em 
2004 na base aérea de Salvador, quando a equipe da TV Globo penetrou na referida unidade e flagrou a destruição da documentação em análise, sendo veiculada a matéria em rede nacional. Posteriormente, a denúncia foi avalizada por perito que, ao analisar os resquícios do material queimado, afirmou categoricamente que era da época em que o país vivia o regime de exceção. Por certo que não é este um caso isolado. Vários militares que, hoje reformados, denunciam a eliminação sistemática de arquivos do regime militar. Concomitantemente, existem alegações no sentido de haver vasta gama de documentos sob a guarda de militares reformados, ou seja, em mãos particulares. Diante de tal situação, não é crível que a União seja a melhor instância para a guarda de tais arquivos, uma vez que nem ao menos consegue manter o acervo pelo qual detém a importante responsabilidade de conservação. Mais um motivo para que se leve a público tal documentação.

De tudo isto, a conclusão inevitável é que se priorizam determinados setores em detrimento do interesse social que possui o conhecimento difundido de tais informações na busca da cidadania e identificação do povo com sua nação. Como já dizia Leonel Brizola (1922-2004), conhecido político e engajado na luta pela redemocratização, a geração daquela época é órfã. Segundo ele, existe uma lacuna no sentimento de agregação nacional, de conhecer o que realmente se passava na época, sem mascaramentos, sem versões parciais ou outros tantos subterfúgios à moda do regime militar. Ainda que tais lacunas lentamente vão sendo, talvez, superadas, à medida que surgem novas informações, fruto da tenacidade de brilhantes estudiosos do assunto, a reconciliação do povo com o seu passado recente poderia ser muita mais rápida caso as informações viessem a público. Ainda, volto a salientar que o conhecimento pleno dos fatos que regeram tal período é imprescindível para que as gerações de hoje e as futuras visualizem o preço a ser pago quando se suprime a democracia. É lastimável que hoje, em tempos de prevalência do Estado Democrático de Direito, ainda se perpetuem resquícios de práticas autoritárias.

\section{POSTURA DOS PAÍSES VIZINHOS A RESPEITO DO TEMA}

Em tempos de polarização ideológica em escala global, os países latinoamericanos não foram exceção a esta regra. A chamada Guerra Fria, conflito ideológico 
entre capitalismo e comunismo, travou consideráveis "batalhas" envolvendo o Brasil e seus países vizinhos. Na época, o fenômeno do populismo - com um certo tempero de esquerda - era predominante nos países da região, inclusive no caso brasileiro. Os Estados Unidos, com receio de que pudesse ocorrer no continente a onda de "esquerdização" pela qual passou o leste europeu, veladamente estimulou forças políticas antagônicas à situação nos respectivos países da América do Sul, de modo que, tendo conhecimento da efervescência política típica daqueles anos e que a ideologia das forças militares thes era mais conveniente - as mesmas resultaram de influência direta da ideário militar americano, notadamente no Brasil, através da Escola Superior de Guerra - lançaram mão de práticas objetivando fortalecer a espinha militar nos respectivos países sul-americanos, nunca encorajando o golpe em si, mas dando suporte a iniciativas internas que pudessem levar a tal resultado. Frente a tal contexto, irrompeu nestes países uma onda de golpes militares patrocinados, mesmo que indiretamente, pelos Estados Unidos. Porém, tanto na forma como se deu a queda dos governos legalmente constituídos, como também na consolidação, enfraquecimento, repercussões humanitárias dos regimes de exceção e posterior retomada do caminho democrático, existiram diferenças significativas destes processos nos países latino-americanos. Conforme detalha Felix (2007):

No Brasil, em 21 anos de regime militar, houve 300 mortos elou desaparecidos, 25 mil presos políticos e 10 mil exilados. Na Argentina, em sete anos de ditadura (1976-1983), os mortos elou desaparecidos foram $30 \mathrm{mil}$, assim como os presos políticos, e os exilados 500 mil. Finalmente, no Chile, em 17 anos da ditadura Pinochet, morreram ou desapareceram 5 mil pessoas, houve 60 mil presos políticos e 40 mil exilados.(FELIX, 2007).

Além disso, ao contrário do caso brasileiro, os países vizinhos acometidos da moléstia dos regimes ditatoriais no período em que o Brasil o fora, tais como a Argentina, Uruguai, Paraguai, Chile e Peru - ditaduras que, consideravelmente, violaram mais os direitos humanos se comparadas ao Brasil - tão logo restabelecido o regime democrático, tornaram públicos os arquivos do referido período ${ }^{2}$, bem como iniciaram um processo de punição dos torturadores, desde os executores até os agentes de cúpula donde emanavam as diretrizes aos órgãos inferiores, além de lançarem mão de iniciativas no sentido de amenizar o sofrimento do povo, tais como a concessão de indenizações 
por prejuízos sofridos. Ainda, constate-se que estes países encontram-se em um estágio de reconciliação e afirmação de suas identidades nacionais muito mais avançado do que no caso brasileiro. Exemplo bastante claro de tal fenômeno é o fato da atual presidente do Chile, Michelle Bachelet, ter sido perseguida e quase morta pela ditadura militar chilena. O interessante é que antes de ocupar o referido cargo, fora Ministra da Defesa, nutrindo uma relação bastante estável e centrada com o setor militar do seu país. Por terem, os chilenos, tido a altivez e coragem de expor o contexto funesto por que passaram boa parte de suas vidas, tiveram a possibilidade de iniciar um processo de superação de tal panorama. Em vias de reconciliação nacional, ainda que existam por parte de alguns setores arcaicos da sociedade a reverência por atitudes antidemocráticas em determinadas situações, hoje o Chile concentra as suas forças em fomentar o seu crescimento e no processo natural de sua afirmação geopolítica na região e no mundo.

De tudo isto, mostra-se suficientemente evidenciada a exigência de que a verdade em relação aos acontecimentos do regime militar seja revelada, de forma a suplantar pressões minoritárias e injustificadas em sentido contrário, fazendo, por fim, que prevaleça o interesse geral e, conseqüentemente, o estado democrático de direito em suas mais plenas acepções.

\section{MINISTÉRIO PÚBLICO E A AÇÃO DIRETA DE INCONSTITUCIONALIDADE $\mathbf{N}^{\circ}$ 4.077: GUARDA E RESPEITO À CONSTITUIÇÃO FEDERAL COMO FUNDAMENTOS DA DEMOCRACIA}

Já existe posição consolidada por parte do Ministério Público a respeito do tema. Tanto é que o Procurador Geral da República, chefe do Ministério Público do Brasil, ajuizou ADIN (ação direta de inconstitucionalidade) contra a Lei no 11.111 de 2005 e artigo 23 da Lei 8.159 de 1991. Argumenta o chefe do parquet serem inconstitucionais os citados dispositivos legais, uma vez que os mesmos estariam em desacordo com os ditames da Constituição Federal, conforme teor do art. $1^{\circ}$, caput, II e parágrafo único; art. $5^{\circ}$ caput e incisos II, III, IV, IX, X, XIV, XXII, XXXIII, XXXIV, “b”, XLI, XLIII, XLIV, XLVV, “e”, LXIV, LXXII e $\S \S 2^{\circ}$ e $8^{\circ}$; art. 62, caput e $\S 1^{\circ}$, I, "a"; art. 68, § 1", II; art. 144 caput; 205 caput; 215 caput; 216 caput; art.220, caput e $\S 1^{\circ} ; 226$ caput e $\S$

2 Parte considerável dos documentos que vieram a público nestes países é oriunda dos arquivos da CIA. Aliás, neste quesito, os Estados Unidos possuem uma política de colaboração com a reconstituição dos fatos daquela época. 
$8^{\circ}$; além dos arts. $8^{\circ}$ e $9^{\circ}$ do ADCT. Expondo-se de forma sucinta, o Ministério Público sustenta que a Lei 11.111 de 2005, originada da conversão da MP (Medida Provisória) 228 de 2004, seria eivada de vício de origem, uma vez que não preenchidos os requisitos de relevância e urgência quando da edição da referida Medida Provisória. Ademais, não é dada ao Executivo a permissão de legislar por meio de MP sobre matérias que versem a respeito de cidadania e direitos políticos. Também, argumenta o Procurador Geral da República que as modificações trazidas pela Lei de 2005, notadamente as contidas em seus artigos $3^{\circ}$ e $4^{\circ}$, concentram o poder decisório no tocante à divulgação ou não das informações do regime militar, exclusivamente nas mãos da União. Assevera ainda o fato de, com o advento da lei em comento, ter-se criado um instrumento para procrastinar indefinidamente o sigilo de tais dados, sendo que é do interesse geral que a nação tome conhecimento de tais fatos. Também, entende violar o princípio constitucional da razoabilidade e da proporcionalidade o prazo de até 100 anos, estabelecido no artigo 23, $\S 3^{\circ}$ da Lei 8.159 de 1991, para que sejam divulgados os dados do regime que contenham alguma referência no que diz com a honra e a imagem das pessoas ali elencadas. Por derradeiro, o Ministério Público colaciona interessante e variada gama de precedentes da Corte Interamericana de Direitos Humanos, denotando que a solução mais coerente diante da nova ordem democrática e o respeito aos direitos humanos é a divulgação, em tempo razoável, dos arquivos de regimes militares instalados outrora na região e que tal aclaramento não deve se restringir aos familiares dos mortos pelas ditaduras, e sim deve atingir amplitude geral, como uma forma de valorização e consolidação da democracia no continente. Abaixo, com o fim de melhor ilustrar o que aqui é posto, colaciono trecho da petição inicial da ADIN, quando o chefe do parquet cita entendimento da Corte Interamericana de Direitos Humanos: “essas medidas não só beneficiam aos familiares das vítimas, mas também a sociedade como um todo, de maneira que o conhecimento da verdade sobre os fatos alegados tenha a capacidade de preveni-los no futuro.”.

Portanto, o Ministério Público, como um dos baluartes na defesa da aplicação da lei, sobriamente, firmou entendimento de que os documentos devem ser plenamente divulgados à população, de forma que, com a propositura da presente ADIN e sua conseqüente apreciação pelo Supremo Tribunal Federal, podemos ainda nutrir 
esperanças de que o sagrado direito à informação e sua inerente contribuição à cidadania dos povos serão respeitados.

\section{CONSIDERAÇÕES FINAIS}

Com a evolução dos tempos e o conseqüente aprimoramento das formas de exercício de poder, a máquina estatal, gradativamente, teve de se adaptar às balizas predominantemente estabelecidas tanto em âmbito interno, como externo. $\mathrm{O}$ respeito aos direitos humanos e aos ditames das constituições nacionais legitimamente elaboradas através dos representantes eleitos pelo povo, servem inegavelmente como limitadores e inibidores de práticas arbitrárias, estas em descompasso com estágio de desenvolvimento atual. Até o presente momento, é questão pacífica que não há outra forma mais aprimorada de gerir uma nação que não seja através da democracia. Está plenamente comprovado que, ao menos no que tange aos direitos mínimos dos indivíduos, este sistema, desde que não desvirtuado, não demonstrou consideráveis falhas, ao contrário dos demais, fadados ao fracasso neste quesito essencial. Porém, paga-se um preço pela adoção do Estado Democrático de Direito e a construção das nações através da participação do seu povo. Imperioso que, quando necessário, se abra mão de valores menores, valores supérfluos se comparados com os direitos tutelados pela democracia. Por sua vez, determinados indivíduos - e são vários - não estão comprometidos com esta lógica, de modo que, equivocadamente, pois a democracia é um sistema plural e válido para todos, preferem ver-se tolhidos em sua liberdade. Tudo isto por não entenderem a necessidade de se estabelecer prioridades e ou porque os valores ditos como imprescindíveis a uma vida digna para a maioria das pessoas, em suas concepções, não galgam tal destaque. Posteriormente, quando da supressão deste "mínimo viver", tais agentes dão-se por conta de que não é válido tal sacrifício, porém, na maior parte das vezes, a situação posta mostra-se irreversível. Costumeiramente no Brasil, a falta de democracia só é sentida quando somos diretamente afrontados em nossas liberdades. Percebe-se a doença apenas quando em estágio avançado, sendo a cura mais complicada nestas circunstâncias. O planejamento de um país democrático deve ser realizado a longo prazo, e a luta pela democracia, de forma constante. Por isso tudo que a defesa permanente deste regime aberto e plural, apesar de tarefa árdua frente à pequenez de 
muitos e aos casuísmos presentes predominantemente na vida das nações que ainda não galgaram uma estabilidade institucional, é imprescindível à manutenção e paulatino aprimoramento da interação entre súditos e os detentores do poder, evitando abusos das mais variadas formas e que o interesse de uma minoria prevaleça. Na complicada incumbência de preservação do regime democrático, o direito à informação é um dos instrumentos de primeira magnitude na efetivação de tal sistema. É ele quem instrumentaliza a tão importante participação do indivíduo na construção do espaço onde interage. Através da informação, propicia-se ao povo um senso de coletividade, a idéia de que faz parte de um sistema muito maior, e desta forma, sendo peça desta engrenagem, exerce seu papel na busca pelo incansável aperfeiçoamento deste todo.

Frente a tal panorama, considerando-se que o Brasil é um país democrático, com o direito à informação inclusive positivado na Constituição Federal, o fato de o governo lançar mão de práticas com o intuito de procrastinar indeterminadamente a divulgação dos arquivos do regime militar, isto sem nenhum motivo plausível e razoável conforme já fora demonstrado anteriormente, além de ser flagrantemente inconstitucional, fere os anseios legítimos de um país cada vez mais democrático, perpetuando injustiças diante da impunidade dos algozes a serviço do Estado de exceção e a dor de muitas famílias que convivem ainda com a triste lógica dos mortos e desaparecidos durante a ditadura militar. Por certo que o objetivo de se dar publicidade aos documentos daquele período, desde que todo o processo seja conduzido de forma séria, não será direcionado a um contexto revanchista, o que temem muitos dos quais se escondem por atrás do conceito de perigo à segurança nacional como pretexto para o sigilo dos arquivos. Apenas que se punam os culpados. Os anseios da sociedade centram-se em resgatar tão funestos acontecimentos para que, futuramente, as próximas gerações não incorram em tais equívocos.

\section{REFERÊNCIAS BIBLIOGRÁFICAS}

ALENCASTRO, Luiz Felipe de. Entrevista com o Professor Luiz Felipe de Alencastro. Revue Scientifique de l'Association des Chercheurs et Etudiants Brésiliens en France. Paris, $\mathrm{n}^{\circ}$ 1-2005, 14 abr. 2005. Entrevista concedida por Cibele Barbosa e Eliana Bueno-Ribeiro. Disponível em: $<$ http://www.apebfr.org/passagesdeparis/edition1/entrevista.html>. Acesso em: 22 jun. 2008. 
COMPARATO, Fábio Konder. Direitos Humanos no Brasil: passado e futuro. São Paulo, $1999 . \quad$ Disponível em: <http://www.pge.sp.gov.br/centrodeestudos/bibliotecavirtual/dh/volume\%20i/artigo\%20 comparato.htm>. Acesso em: 21 jun. 2008.

CORTE INTERAMERICANA DE DIREITOS HUMANOS - Caso de las hermanas serrano cruz vs. El salvador. Sentença de 1/3/2005. Serie C No. $120 \S 169$. Disponível em: <http://noticias.pgr.mpf.gov.br/noticias-do-site/pdfs/adin.pdf>. Acesso em: 22 jun. 2008.

FELIX, Pedro. Ditadura Militar na América Latina. Cuiabá, 2007. Disponível em: <http://atualidades.blog.com/2057684/>. Acesso em: 20 jun. 2008.

MINISTÉRIO DA JUSTIÇA. Site do Ministério da Justiça. Brasília, 2001. Disponível em: <http://www.mj.gov.br>. Acesso em: 20 jun. 2008.

MINISTÉRIO DA CASA CIVIL. Site do Ministério da Casa Civil. Brasília, 2006. Disponível em: <http://www.presidência.gov.br/casacivil>. Acesso em: 18 jun. 2008.

PROCURADORIA GERAL DA REPÚBLICA. Site da Procuradoria Geral da República. Brasília, 2008. Disponível em: <http://www2.pgr.mpf.gov.br>. Acesso em: 18 jun. 2008. 